Dossiê: Ethos Contemporâneo e Religião-Artigo Original (c) (1)

\title{
As diferenças como ethos e práxis contemporâneos: sobre a dialética entre fundamentação e aplicação de paradigmas normativo-religiosos
}

\author{
The differences as contemporary ethos and praxis: on the dialectics between \\ foundation and application of normative-religious paradigms
}

Leno Francisco Danner*

Agemir Bavaresco**

Fernando Danner***

\begin{abstract}
Resumo
Neste artigo, estabelecemos a categoria das diferenças como o ethos e a práxis antropológico-ontológicos e epistemológico-políticos efetivamente contemporâneos, que desafiam-dinamizam as religiões institucionalizadas e universalistas, ao estilo da Igreja Católica, em seu uso de fundamentações essencialistas e naturalizadas como base normativo-paradigmática para o enquadramento, legitimação e orientação dessas mesmas diferenças, como embasamento da dialética entre pluralidade e unidade acerca dessas mesmas diferenças. A partir disso, defenderemos que o desafio central para as religiões institucionalizadas e universalistas neste século XXI - e, no nosso caso, novamente para a Igreja Católica - consiste na desconstrução da correlação entre institucionalismo forte, objetividade antropológico-ontológica e epistemológico-moral estritas e fundamentalismo político-normativo. Nesse sentido, na medida em que também as instituições religiosas trouxerem para dentro de sua dinâmica de constituição, legitimação e fomento do credo as diferenças como práxis normativa e sujeitos epistemológico-políticos da fundamentação, alcança-se um enfraquecimento e uma moderação - e talvez até mesmo um abandono - de fundamentações essencialistas e naturalizadas como base para o enquadramento de todas as áreas da vida humana. Este, de todo modo, conforme pensamos, deve ser o caso de gênero e de sexualidade, que a rigor já não poderiam e nem deveriam mais ser fundados em tais bases essencialistas e naturalizadas.
\end{abstract}

Palavras-Chave: Fundamentação; Aplicação; Diferenças; Institucionalização; Moderação.

\begin{abstract}
In the text, we put the category of differences as anthropological-ontological and epistemological-moral contemporary ethos and praxis which challenge-streamline institutionalized and universalist religions, for example the Catholic Church, in their use of essentialist and naturalized foundations as normative-paradigmatic basis for framing, legitimation and orientation of these differences, as basement for the dialectics between plurality and unity regarding these differences. From that, we will argue that the institutionalized and universalist religions' central challenge - and, in our case again, the Catholic Church's central challenge - consists in the deconstruction of the correlation among strong institutionalism, strict anthropological-ontological and epistemological-moral objectivity and political-normative fundamentalism. In this sense, as long as religious institutions bring the differences as normative praxis and epistemological-political subjects into their internal dynamic of constitution, legitimation and social foment of the creed, it is possible to achieve the weakening and the moderation - and perhaps the own abandonment - of the essentialist and naturalized foundations as basis for framing of all areas of human life. Anyway, as we think, this must be the case for gender and sexuality, which could not and should not be grounded on such an essentialist and naturalized basis.
\end{abstract}

Key-Words: Foundation; Application; Differences; Institutionalization; Moderation.

Artigo recebido em 31 de março de 2017 e aprovado em 30 de junho de 2017.

${ }^{*}$ Doutor em Filosofia (PUC-RS). Professor de Filosofia e de Sociologia no Departamento de Filosofia da Universidade Federal de Rondônia (UNIR). País de Origem: Brasil. E-mail: leno_danner@yahoo.com.br.

** Doutor em Filosofia (Université Paris I - Phanteon Sorbonne). Professor do Departamento de Filosofia e do Programa de PósGraduação em Filosofia da Pontifícia Universidade Católica do Rio Grande do Sul. País de Origem: Brasil. E-mail: abavaresco@pucrs.br.

*** Doutor em Filosofia (PUC-RS). Professor do Departamento de Filosofia e de Sociologia da Universidade Federal de Rondônia (UNIR).

País de Origem: Brasil. E-mail: fernando.danner@gmail.com.

Horizonte, Belo Horizonte, v. 15, n. 46, p. 510-542, abr./jun. 2017 - ISSN 2175-5841 
Ninguém pode ser condenado para sempre, porque esta não é a lógica do Evangelho! Não me refiro só aos divorciados, mas a todos, seja qual for a situação em que se encontrem (Papa Francisco, 2016, § 297, p. 234).

\section{Considerações iniciais}

No texto, nos propomos pensar a correlação de ethos contemporâneo, religião e teologia, no sentido de percebermos como a teologia constitui, legitima e aplica os princípios religiosos nesse mesmo ethos e a partir dele. Por meio da definição genérica do ethos contemporâneo como época das diferenças, do pluralismo antropológico-ontológico, sociocultural e epistemológico-político, refletiremos sobre os desafios postos às religiões institucionalizadas e universalistas e, em particular, à Igreja Católica em termos de constituição e de fundamentação teológicas e de sua aplicação seja dentro do contexto próprio à comunidade católica, seja em termos societais-culturais de um modo mais geral. Nos interessa especialmente pensar a constituição teológica e sua aplicação prática no pluralismo, a partir dele, como o ponto nevrálgico da vida cotidiana hodierna e, nela, da constituição, da fundamentação e da atuação sociocultural e públicopolítica das religiões institucionalizadas e universalistas e em termos de teologia. Com efeito, se partirmos do argumento de que, na contemporaneidade, tanto nas sociedades ocidentais quanto em termos de globalização econômico-cultural, o grande desafio consiste na interrelação (nem sempre pacífica e produtiva) entre as diferenças e as religiões institucionalizadas e universalistas, perceberemos que a dialética entre fundamentação e aplicação de paradigmas institucionais torna-se o cerne da dinâmica de constituição teológica das religiões institucionalizadas e de sua vinculação e papel político-normativos na sociedade e relativamente ao pluralismo.

Nesse sentido, o artigo desenvolverá e defenderá três argumentos centrais: (a) as diferenças e o pluralismo antropológico-ontológico, sociocultural e epistemológico-político representam a base vital da contemporaneidade, o ethos contemporâneo em seu sentido mais fundamental, devendo ser assumidos nessa 
sua centralidade em termos de constituição, legitimação e vinculação sociopolítica das instituições de um modo geral e das religiões institucionalizadas e universalistas em particular; por conseguinte, (b) o grande desafio epistemológicopolítico desse ethos contemporâneo, dada a centralidade, nele, das diferenças, consiste, para as religiões institucionalizadas e universalistas (e, no nosso caso, para a Igreja Católica em particular), na dialética entre constituição e fundamentação teológico-paradigmáticas e sua aplicação no contexto social, político e cultural de um modo mais geral - prova da pungência dessa dialética é o recente documento “A vocação da família na Igreja e no mundo contemporâneo", resultante do $14^{\circ}$ Sínodo dos Bispos, e a consequente resposta a ele na forma da encíclica papal Amoris Laetitia, pelo Papa Francisco, que tematizam diretamente a constituição-fundamentação da teologia e sua aplicação à pluralidade, especialmente em termos de gênero, sexualidade e, aqui, família; e (c), por fim, de que a dialética entre constituição-fundamentação teológica e sua aplicação desde as instituições, uma vez afirmando as diferenças como base do ethos contemporâneo e ponto de partida das próprias instituições, deve levar à moderação no que diz respeito à utilização de fundamentações essencialistas e naturalizadas e sua aplicação desde um modelo e uma práxis em termos de institucionalismo forte, o que poderia significar a renúncia em utilizar-se fundamentações essencialistas e naturalizadas em certas áreas da vida humana, como no caso de gênero e de sexualidade - e, sobretudo, na sensibilidade, no discernimento e na moderação dos sujeitos epistemológico-políticos institucionalizados em seu enquadramento via teologia das diferenças.

\section{Ethos contemporâneo como pluralismo-intersubjetivdade: as diferenças, a fundamentação e a aplicação institucionais}

A condição fundamental de qualquer reflexão antropológico-ontológica (a concepção de ser humano como uma visão de mundo) e epistemológico-moral (os paradigmas crítico-normativos que correlacionam, enquadram, dinamizam e legitimam o eixo socialização-subjetivação) é exatamente a intersubjetividade, a 
sociabilidade, o que significa dizer: a pluralidade de visões de mundo em termos antropológico-ontológicos, a profusão de fundamentações normativas e a alteridade-multiplicidade dos sujeitos epistemológico-políticos. As reflexões e incursões práticas em termos ético-políticos e as fundamentações antropológicoontológicas, quando lançamos um olhar à história, à constituição e à evolução da cultura ocidental - mas também quando nos debruçamos e analisamos a história de qualquer sociedade-cultura, ou principalmente o modo como qualquer sociedade-cultura se autocompreende normativamente ao longo do tempo - têm como foco central, como leitmotiv basilar, o enquadramento, a organização e a harmonização dessa pluralidade amorfa, de modo a enfatizar e fomentar suas qualidades, realizar suas potencialidades e resolver seus déficits (cf., por exemplo: PLATÃO, 2002; ARISTÓTELES, 1991, 1997; SANTO AGOSTINHO, 1991; TOMÁS DE AQUINO, 1997; MARX, 2013; MARX \& ENGELS, 2008; RAWLS, 2002; HABERMAS, 2002, 2003; KOPENAWA \& ALBERT, 2015 - diferentes perspectivas, passadas e contemporâneas, que tratam exatamente da fundamentação-aplicação como práxis de posições antropológico-ontológicas e epistemológico-morais relativamente aos eixos socialização-subjetivação e pluralidade-unidade). Interessantemente, em primeiro, lugar, é no eixo socialização-subjetivação que está não apenas o segredo da evolução sociocultural e da constituição de paradigmas normativos e de instituições deles guardiães, legitimadoras e fomentadoras, mas também o próprio cerne da aplicação enquanto práxis desses mesmos paradigmas antropológico-ontológicos e epistemológicomorais que, enquanto instrumentos político-normativos (e calcados em visões de mundo e de homem, como visões de mundo e de homem), enquadram, constroemreconstroem e orientam-reorientam a constituição, a formação e a transformação do eixo socialização-subjetivação.

Portanto, em segundo lugar, na correlação entre teoria e prática utilizaremos, a partir de agora, o termo práxis para significar essa imbricação viva, dinâmica e sempre atuante e vinculada - há uma carnalidade e uma politicidade pungentes e orgânicas da práxis fundamentadora, corretiva e transformadora que 
desde sempre e para sempre coloca o eixo socialização-subjetivação como a matéria e o lócus totalmente presentes e contemporâneos da ação humana sobre si mesma e para si mesma ao longo do tempo. É nesse sentido, aliás, que atuamos sobre nós mesmos em termos constitutivos e evolutivos e, com isso, assumimos, significamos-ressignificamos e criamos-recriamos toda a práxis legada pelas gerações passadas: como trabalho de nós sobre nós mesmos, dada exatamente a atualidade-contemporaneidade da práxis humana como vida-ação sociocultural sobre si mesma por si mesma. Aqui, aquela afirmação de Comte, de que nós, os vivos, somos basicamente governados pelos mortos, pelo passado calcificado, não é totalmente - e nem fundamentalmente - verdadeira, posto que nós estamos sempre enquadrando, pensando-repensando, construindo-reconstruindo nossa vida sociocultural e como vida sociocultural ativa, vinculada: o presente nos é práxis e, por isso, trabalho crítico-reflexivo, desconstrutivo e construtivo. Portanto, reforçamos, a práxis da fundamentação e da realização-aplicação teórico-prática não é e nunca será uma tarefa de gabinete, de assepsia e de neutralidade axiológicas; ela é materialidade, politicidade e carnalidade no sentido mais estrito destes termos. Ela é a própria socialização-individuação em sua autoconsciência, isto é, em sua autotematização, autolegitimação, autoconstituição e autotransformação ao longo do tempo. Não existirá nunca, aqui, a separação entre teoria e prática, a divisão entre a instituição e a vida cotidiana, entre o sujeito epistemológico-político institucionalizado e o sujeito da práxis - trata-se de um positivismo barato que não tem lugar nas ciências humanas e sociais, incluindo-se, aqui, as ciências da religião de um modo geral e a teologia em particular (elas são práxis e se definem na práxis).

Note-se, com isso, que estamos apontando para a dialética entre fundamentação e aplicação das teorias como algo político, carnal, normativo, como práxis, portanto. É essa dialética que torna dramática, pungente e tensa a evolução social enquanto correlação de socialização e de subjetivação, na medida em que a define sempre como um trabalho atual, contemporâneo dos seres humanos sobre si mesmos, das sociedades-culturas sobre si mesmas, dos sujeitos epistemológico- 
políticos sobre si mesmos e em termos de práxis intersubjetiva criadora. É essa dialética que torna dramáticos, pungentes e tensos o enquadramento, a intervenção, a crítica e a orientação-reorientação da correlação socializaçãosubjetivação. E ela assim o faz exatamente porque a base socialização-subjetivação é, por definição, a atuação da pluralidade sobre si mesma, a dialética da pluralidade sobre si mesma, as interações, os conflitos, as hegemonias, as sínteses e, com isso, a multiplicidade de sujeitos epistemológico-políticos e de posições antropológicoontológicas que fazem parte do mosaico e do horizonte normativos, culturais e políticos de qualquer contexto sociocultural ou mesmo mais além (pensemos, aqui, na globalização cultural-econômica ou nos conflitos interculturais e interreligiosos) ${ }^{1}$. Aqui, a dialética entre legitimação e aplicação é quem expressa, primeiro, a pluralidade em interação-conflito e, segundo, a gradativa hegemonia de posições antropológico-ontológicas e epistemológico-morais, o que significa dizerse, terceiro, que a práxis de enquadramento, intervenção, crítica e orientaçãoreorientação é quem efetivamente torna problemáticas, tensas e às vezes violentas a evolução social e a aglutinação da pluralidade. É dela e para ela que convergem todas as interações e todos os conflitos sociais; é nela e para ela que aparecem e desaparecem todos os sujeitos epistemológico-políticos em suas interações e lutas, como interação e luta permanentes e pungentes, o que mostra, mais uma vez, a carnalidade, a politicidade e a materialidade da práxis, por causa exatamente das interações e das lutas assumidas e dinamizadas pela multiplicidade de sujeitos epistemológico-políticos.

Ora, é o eixo fundamentação-aplicação da práxis e como práxis que nós consideramos a chave de leitura e o núcleo normativo da evolução sociocultural e da constituição institucional. Com efeito, esse eixo nos permite, em primeiro lugar, entrever a hegemonia política, normativa e epistemológica de paradigmas antropológico-ontológicos e epistemológico-morais, com sua consequente

\footnotetext{
${ }^{1}$ Como diz Axel Honneth (2003, p. 156), "são as lutas moralmente motivadas de grupos sociais, sua tentativa coletiva de estabelecer institucional e culturalmente formas ampliadas de reconhecimento recíproco, aquilo por meio do qual vem a se realizar a transformação normativamente gerida das sociedades".
} 
institucionalização. Ele nos permite entrever, em segundo lugar, o próprio fenômeno da institucionalização das visões de mundo antropológico-ontológicas e epistemológico-morais e o modo como concebem, enquadram, intervêm e orientam-reorientam os processos de socialização-subjetivação, o que significa que a institucionalização como práxis - e não como exercício teórico puro, nãointencionado, sem carnalidade e sem politicidade - e na práxis - portanto, sempre e totalmente vinculada político-normativamente - nos leva diretamente ao cerne da sociabilidade-intersubjetividade como dialética entre pluralidade e unidade, possibilitando-nos, assim, a avaliação de como essa pluralidade própria à sociabilidade encontra homogeneização e dinamização ao longo do tempo, o quanto suas diferenças e identidades internas, suas interações e conflitos e seus respingos institucionais, assim como seus sujeitos epistemológico-políticos, são assumidos, marginalizados e dinamizados - a institucionalização como sendo o elemento da intersecção entre práxis e enquadramento-intervenção, entre pluralidade e unidade, da socialização-subjetivação, da fundamentação e da aplicação.

A fundamentação-aplicação dos paradigmas normativos pelos sujeitos epistemológico-políticos entre si e em termos de intersubjetividade politizante, encarnada e vinculada está diretamente ligada à pluralidade-unidade, o que demonstra a centralidade da sociabilidade-intersubjetividade e, aqui, da práxis como o eixo da constituição, da dinamização e da evolução sociocultural. A vida sociocultural e, a partir daqui, a definição do status quo, das estruturas institucionais e do horizonte e dos valores normativo-simbólicos acontecem exatamente a partir dessa interação e do conflito intersubjetivos, socialmente vinculados, de modo que as inter-relações e as disputas entre os sujeitos epistemológico-políticos ao longo do tempo em sua busca por hegemonia, em sua aproximação e distanciamento, naquilo que os une e em tudo o que os separa, acabam dando organicidade, dinamicidade e conteúdo à dialética socializaçãosubjetivação, pluralidade e unidade. Por meio dessa correlação entre fundamentação e aplicação, percebemos, com isso, os próprios grupos 
socioculturais, os próprios sujeitos epistemológico-políticos em suas interações e conflitos, com sua hegemonia e contrapontos.

Desse modo, aparece como ponto nodal da práxis o fato de que a dialética socialização-subjetivação enquanto base da constituição, problematização e evolução sociocultural e institucional é sempre baseada na e dependente da interação (o que também significa conflito) entre os sujeitos epistemológicopolíticos em termos de práxis, na práxis, como práxis. É por isso, aliás, que Habermas sempre defendeu enfaticamente, em sua teoria da modernidade, que, pelo fato de ser fundada normativa e politicamente com base nessa pluralidade, "a sociedade tem de ser integrada, em última instância, através do agir comunicativo" (HABERMAS, 2003, p. 45; os destaques são de Habermas), que tem por base a centralidade epistemológica, política e normativa das diferenças e de suas relações mútuas. Na mesma esteira, essa dialética entre socialização e subjetivação, e como práxis interativa-conflitiva entre os diversos grupos socioculturais, segundo Honneth, constitui-se como processo que "está ligado ao pressuposto de uma ampliação simultânea das relações de reconhecimento" (HONNETH, 2003, p. 156). Essa dialética expressa, por conseguinte, dois pontos fundamentais quando pensamos a questão fundamentação-aplicação dos paradigmas normativos, antropológico-ontológicos e epistemológico-morais socialmente vinculantes e política e institucionalmente nucleares: primeiro, a pluralidade sociocultural de visões de mundo, de paradigmas normativos e de sujeitos epistemológico-políticos necessita uniformizar-se minimamente, necessita de uma certa base política, normativa e institucional comum como árbitro e médium da intersubjetividade cotidiana, da evolução sociocultural enquanto movimento da pluralidade sobre si mesma e para si mesma; segundo, é exatamente como pluralidade que essa dialética entre socialização-subjetivação com vistas à consecução da identidade social, da homogeneidade e unidade socioculturais acontece e é dinamizada, o que significa dizer-se que a pluralidade dos sujeitos epistemológico-políticos (e suas consequentes visões de mundo antropológico-ontológicas) torna-se política e normativamente o eixo para o entendimento da dinâmica social, dos arranjos 
sociais e, em última instância, dos códigos e dos valores normativos assumidos por uma sociedade e por suas instituições ao longo do tempo.

Nesse sentido, queremos afirmar-defender exatamente o argumento de que a institucionalização é práxis e deve ser entendida como práxis que tem politicidade, carnalidade e materialidade, isto é, que está vinculada, que é totalmente política e politizante, que lida diretamente com a pluralidade dos sujeitos epistemológico-políticos e que, por causa disso, gera e dinamiza efeitos político-normativos, estados de ânimo individuais e grupais, além de tornar legítimos ou ilegítimos modos de vida, sujeitos epistemológico-políticos e possíveis arranjos e caminhos institucionais-normativos: nesse sentido, a instituiçãoinstitucionalização é o médium entre pluralismo e unidade e ela expressadinamiza-orienta a dialética das contradições e das sínteses sociais a partir do enquadramento e da condução dos sujeitos epistemológico-políticos atuantes social e institucionalmente. Ou seja, é por incidir sobre a pluralidade com o objetivo de unificá-la e de homogeneizá-la naquilo que aquela pluralidade de visões antropológico-ontológicas e sujeitos epistemológico-políticos têm - ou deveriam ter - em comum que a instituição-institucionalização é a dialética-chave para entender-se o sentido complexo e político-normativo da evolução social enquanto correlação de pluralidade e unidade, diferenças e homogeneidade. Ela mostra-se na e mostra a práxis vital enquanto uma interação (que também é conflito, repetimos mais uma vez) permanente e pungente entre os sujeitos epistemológico-políticos, que leva a sínteses e contradições que tanto moldam e redefinem as instituições, o status quo e a hegemonia ao longo do tempo quanto garantem, com isso, a permanente tematização e reelaboração da vida social por parte dos sujeitos epistemológico-políticos enquanto uma práxis atual, sempre aberta e em construção.

Desse modo, as correlações pluralidade-unidade e institucionalizaçãosocialização nos permitem pensarmos sobre três pontos que nos parecem muito caros para entendermos, hoje, como práxis atual, a imbricação, a mútua 
dependência e o mútuo suporte de fundamentação normativa e aplicação epistemológico-política dessa mesma fundamentação na pluralidade com vistas à sua unidade, institucionalmente legitimada e guiada, a saber: primeiro, a pluralidade é o ponto de partida para se pensar essa mesma objetividade antropológico-ontológica e epistemológico-moral, e não o contrário, o seu ponto de chegada - com isso, a pluralidade é a condição paradigmática, a condição de qualquer possível objetividade antropológico-ontológica e epistemológico-moral, e não o contrário, isto é, aquela teimosa noção parmenídico-platônica (assumida depois, como veremos adiante, pelas religiões institucionalizadas e universalistas ao estilo da Igreja Católica) de que a unidade é a base do sentido da pluralidade amorfa, cega e incompleta, aquela como base ontogenética desta; segundo, as sínteses e as contradições dos paradigmas antropológico-ontológicos e epistemológico-políticos são devidas à interação e ao conflito permanentes entre os sujeitos epistemológico-políticos como práxis e na práxis, como vinculação e atuação políticas vivas, significantes e politizantes, o que significa que a pluralidade dos sujeitos epistemológico-políticos não é apenas a base da objetividade antropológico-ontológica e epistemológico-moral, como dissemos logo acima, senão que também o sujeito da práxis e como práxis, os sujeitos que, por meio de suas interações, assumem, elaboram-reelaboram, constroem-reconstroem a evolução social, a estruturação das instituições e do status quo e a hegemonia paradigmática e sua influenciação política e politizante; terceiro, a instituiçãoinstitucionalização é exercício que se funda na e que dinamiza a dialética entre diferenças e identidade, pluralidade e unidade, permitindo a institucionalização paradigmática e sua correlação com formas diversas - mas interligadas - de poder que possibilitam o enquadramento e o trabalho de moldagem dessa mesma pluralidade, ainda que tal trabalho de enquadramento e de moldagem não seja totalmente direto e sem contraposições, senão que resultado sintético, contraditório e reelaborado do fato de que a pluralidade de sujeitos epistemológicopolíticos não pode ser desfeita ou apagada ou negada, permanecendo sempre viva e atuante. 
Nós acreditamos que a época contemporânea - e não nos referimos apenas ao contexto das sociedades de modernização cultural e econômico-política ocidentais, senão que também ao contexto da própria globalização econômicocultural consolidado concomitante e correlatamente - torna totalmente pungentes e dramáticos estes três momentos acima mencionados: a pluralidade como base ontogenética da unidade; a pluralidade de sujeitos epistemológico-políticos como os artífices da práxis e como práxis, a partir de suas inter-relações e conflitos ao longo do tempo; e a institucionalização como política, de base política, de sujeitos políticos e de impactos diretamente político-normativos no dia a dia da vida cotidiana e sobre a pluralidade de formas de vida antropológico-ontológicas e de sujeitos epistemológico-políticos. Em verdade, o ethos contemporâneo tem nas diferenças e como pluralização dos sujeitos epistemológico-políticos e das visões de mundo antropológico-ontológicas, sua base normativa, sua dialética políticoevolutiva e seu sujeito epistemológico-político da práxis fundamentais (cf.: LÉVINAS, 1997, p. 21-33; RAWLS, 2002, p. 45-90; HABERMAS, 2002, p. 19-22; HONNETH, 2007, p. 61-65; FORST, 2010, p. 143-144). Nesse sentido, a institucionalização - em qualquer área da vida cotidiana que se possa imaginar, da política à economia e passando pela cultura, pela religião e pela educação etc. - de formas de vida, de paradigmas normativos e de sujeitos epistemológico-políticos se torna um ponto fundamental, mas ao mesmo tempo problemático, denso e contraditório, no que diz respeito à dialética pluralidade-unidade, diferençasidentidade, institucionalização-socialização-subjetivação (RORTY, 2010, p. 11-24; RAWLS, 2002, p. 179-219; HABERMAS, 2003, p. 22-34).

Ora, na medida em que a institucionalização impacta e dinamiza a dialética diferenças-identidade, pluralidade-unidade e, ao mesmo tempo e para isso, assume a função de fundamentação e de aplicação de paradigmas normativos via política e educação à pluralidade com vistas a torná-la una, homogênea, dotando-a de identidade coletiva, ela é obrigada, como condição disso e para isso, a tematizar epistemológica e normativamente a pluralidade e a aplicar política e pedagogicamente seus paradigmas nessa mesma pluralidade a partir de uma 
perspectiva centralizada, unívoca e estandardizada. Aqui a dialética pluralidadeunidade, diferenças-identidade adquire seu sentido vivo, político-politizante e engajado como práxis e na práxis. Aqui, portanto, ela mostra toda sua força e constituição político-normativas; ela faz da práxis intersubjetiva e sob a forma de interação-conflito o núcleo vital, político e normativo, antropológico e ontológico, onde os sujeitos epistemológico-políticos confrontam-se e às instituições, onde eles apresentam-se como os artífices da evolução social e dão sentido e dinamicidade e pungência às instituições. Essa dialética entre institucionalização e vida social, entre diferenças e identidade, pluralidade e unidade, é a base de constituição e de dinamização das instituições porque, em primeiro lugar, ela é o núcleo duro, político-normativo, das interações e dos conflitos entre os sujeitos epistemológicopolíticos enquanto construtores da vida sociocultural, de modo que, aqui, essas mesmas instituições são resultado de hegemonia político-normativa e aplicam e reaplicam essa mesma base político-normativa na vida cotidiana sobre os sujeitos epistemológico-políticos. É por isso que vimos falando, ao longo deste artigo, que tal dialética entre diferenças e unidade constitui o cerne da evolução social, das interações e conflitos político-culturais e da constituição e da atuação das instituições, o que faz da práxis o núcleo paradigmático e a chave-de-leitura epistemológico-política para percebermos-tematizarmos as diferenças, suas interações e conflitos, e o papel político-normativo das instituições na vida social e como sujeitos epistemológico-políticos ampliados. Novamente, na fundamentação e na aplicação dos paradigmas antropológico-ontológicos e epistemológicopolíticos podemos perceber o sentido, o caminho e os impactos da instituiçãoinstitucionalização na vida social, frente às diferenças e como sujeito epistemológico-político ampliado.

Dois pontos, nesse sentido, merecem ser ressaltados como dando o tom da constituição, da dinamização e da evolução de nosso ethos contemporâneo, a saber, (a) as diferenças e (b) a instituição-institucionalização e, com isso, a dialética entre diferenças e identidade, pluralidade e unidade que perpassa a constituição da sociedade-cultura, a atuação dos sujeitos epistemológico-políticos vários e a 
estruturação, o funcionamento e a vinculação socioculturais e normativas das instituições. O primeiro ponto importante, desse modo, quando falamos em ethos contemporâneo, está exatamente nas diferenças: estas diferenças é que constituem e dinamizam esse mesmo ethos contemporâneo, de modo que estamos na época das diferenças, para as diferenças e pelas diferenças como esse elemento atual epistemológico-politicamente e fundante antropológico-ontologicamente. Não por acaso, o grosso das teorias antropológicas, sociológicas, filosóficas e pedagógicas de meados do século XX em diante têm nas diferenças essa categoria epistemológicopolítica e essa base antropológico-ontológica que orienta e impacta a constituição dos paradigmas normativos que abordam a pluralidade de visões de mundo e de sujeitos epistemológico-políticos, definindo também o tipo de abordagem políticoinstitucional em termos de aplicação, enquadramento, crítica e orientação da vida social em sua multiplicidade de práticas, de valores, de relações e de sujeitos epistemológico-políticos.

As diferenças, com isso, enquanto categoria epistemológico-política e antropológico-ontológica fundamental são a base da construção dos paradigmas normativos e da constituição-legitimação-dinamização da práxis - elas são a práxis fundamental, o único buraco de agulha por meio do qual toda teoria epistemológico-política e toda visão de mundo antropológico-ontológica têm de passar se quiserem adquirir legitimidade normativa e apoio e atuação políticocultural $^{2}$. Esse, pelo menos, é um fato basilar das sociedades modernas, das democracias liberais ocidentais, como reconhecem Rawls, Habermas, Honneth e Forst: o pluralismo é o ponto de partida tanto para a fundamentação quanto para a aplicação dos paradigmas e para a estruturação-atuação das instituições, assim como seu ponto de chegada, o que impacta severamente as fundamentações essencialistas e naturalizadas, assumidas por instituições religioso-culturais como

\footnotetext{
${ }^{2}$ Nunca é demais recordar uma invectiva fundamental de Lévinas relativamente às tentativas de unidimensionalização e de enquadramento estritos em relação às diferenças, algo, no fim das contas, somente possível por meio da própria negação e da exclusão direta das diferenças como diferenças: "Nossa relação com outrem consiste certamente em querer compreendê-lo, mas essa relação excede a compreensão. Não só porque o conhecimento de outrem exige, além de curiosidade, também simpatia e amor, maneiras de ser distintas da contemplação impassível. Mas também porque, na nossa relação com outrem, este não nos afeta a partir de um conceito. Ele é ente e conta como tal" (LÉVINAS, 1997, p. 28; os destaques são nossos).
} 
base de sua constituição, legitimação e evolução ao longo do tempo, em especial quando se fala em vinculação sociopolítica dessas mesmas instituições religiosoculturais e sua atuação em termos de esfera público-política (cf.: RAWLS, 2002, p. 24-25; HABERMAS, 2002, p. 134-135; HONNETH, 2003, p. 275-280; FORST, 2010, p. 40, p. 281, p. 345-346).

O segundo ponto importante, acima comentado, é constituído-representado pela instituição-institucionalização como a base estruturadora da constituição sociocultural e de sua evolução ao longo do tempo, o que significa dizer-se que as instituições (religioso-culturais, sociopolíticas, científicas, educacionais, econômicas etc.) são tanto o médium que interliga tendências evolutivas gerais e a multiplicidade de sujeitos epistemológico-políticos, o médium que interrelaciona essa multiplicidade de sujeitos epistemológico-políticos, quanto um macrossujeito epistemológico-político efetivo, centralizador e condutor da evolução, um macrossujeito epistemológico-político que é hegemônico em relação a outros sujeitos epistemológico-políticos marginais, fundando sua constituição, legitimação e atuação socialmente vinculantes em uma posição antropológico-ontológica e a partir de uma práxis político-normativa particulares que se colocam como gerais, universais, como guarda-chuva normativo de toda a pluralidade, para toda a pluralidade e por toda a pluralidade (portanto, nesse caso, o ponto de partida seria a unidade como condição da pluralidade). Esta é uma herança da filosofia platônica assumida em cheio pela teologia medieval e, depois, pela ciência natural moderna depois, ainda, pelo Estado burocrático-administrativo e pelo mercado capitalista -, isto é, a correlação entre institucionalização, objetividade epistemológico-moral e antropológico-ontológica e justificação, a mútua imbricação entre instituiçãoinstitucionalização e/como macrossujeito epistemológico-político que tem - ele e somente ele - legitimidade para, no seu campo específico de atuação, constituir, legitimar e orientar a formação, a aplicação e o fomento público de seu credo, de seus valores centrais e da própria evolução sociocultural. A instituição seria o sujeito epistemológico-político fundamental da práxis e, com isso, a institucionalização seria a práxis político-normativa por excelência da constituição, 
legitimação e evolução de si mesma e, de um modo mais geral, da própria vida sociocultural.

Ora, é aqui que podemos situar a dialética entre instituiçãoinstitucionalização e diferenças, a dialética entre diferenças e unidade, enquanto o cerne antropológico-ontológico e epistemológico-político tanto para a construção de paradigmas normativos quanto para a realização da evolução social, tanto para a fundamentação normativa da práxis quanto para sua aplicação institucionalmente guiada, orientada, definida (como práxis). Com efeito, duas tendências muito claras e em geral contrapostas confrontam-se aqui, explodem aqui: primeiro, o fato de que as diferenças são por excelência não-homogeneizáveis, não podendo ser apagadas ou negadas ou enquadradas de modo estrito a não ser por sua negação enquanto diferenças, a não ser por seu silenciamento epistemológico-políticonormativo e mesmo material (em termos de genocídio e violência física); segundo, o fato de que a instituição-institucionalização trabalha a partir da centralização e monopolização da constituição, legitimação e fomento social do credo, de modo que este estaria, em grande medida, sobreposto e independente em relação à participação dos sujeitos epistemológico-políticos plurais, crentes e não-crentes (isso em todas as instituições, da política à economia, da religião à cultura - tratase de uma tendência geral, esta do fechamento e da sobreposição estruturais das instituições em relação aos sujeitos epistemológico-políticos da sociedade, como movimentos sociais, iniciativas cidadãs e minorias religioso-culturais, ou até de crentes e de não-crentes).

Note-se, primeiramente, que a unidade é dada exatamente pela instituição e pela consequente institucionalização como práxis, em que processos homogeneizadores em termos políticos, socioculturais, pedagógicos e epistemológicos acabam aglutinando e orientando a pluralidade de sujeitos epistemológico-políticos e de visões antropológico-ontológicas de mundo. Note-se, em segundo lugar, aquela contraposição acima, entre instituiçãoinstitucionalização e diferenças, que não pode ser entendida, isso deve ficar muito 
claro, como um maniqueísmo puro e simples, senão que apenas como dois pólos constituintes, fundantes e dinamizadores de uma mesma relação-interação, a saber, a sociabilidade, a constituição autorreferencial de uma sociedade-cultura e sua evolução ao longo do tempo. Com isso, não existiria - não é nossa intenção afirmar isso aqui - um lado bom e um lado ruim; queremos apenas chamar a atenção para essa dialética entre diferenças e identidade, pluralidade e unidade como o cerne do processo de constituição, fundamentação e evolução sociocultural, que encontra nas instituições e sob a forma de institucionalização seu eixo estruturador e sua chave de leitura epistemológico-política fundamentais. Ora, nesse quesito, a sociedade-cultura se constitui, se autolegitima, transforma-se e, com isso, evolui ao longo do tempo por causa dessa dialética, por causa dessa interação e desse conflito que levam à hegemonia (isto é, à institucionalização) de sujeitos epistemológico-políticos, concepções antropológico-ontológicas e valores e práticas normativos socialmente vinculantes e estruturadores tanto das instituições quanto de sua práxis homogeneizadora, que enquadra, dirige e configura o processo de socialização e de subjetivação, totalmente correlacionado.

Essa práxis homogeneizadora, institucionalmente centralizada, gerida, legitimada e conduzida exatamente a partir da hegemonia de sujeitos epistemológico-políticos e posições antropológico-ontológicas particulares, enquadra as diferenças e a pluralidade a partir da busca pela unidade, a partir da própria afirmação da unidade como condição tanto da objetividade epistemológicomoral e antropológico-ontológica quanto do entendimento, da participação e da dinamização da vida sociocultural e dos sujeitos epistemológico-políticos vários. Institucionalizar é, em grande medida, unidimensionalizar as diferenças, apagando muitas de suas especificidades, minimizando-as como diferenças. Ora, isso é tanto mais verdade quando pensamos em instituições religioso-culturais fundadas em e dinamizadas por fundamentações essencialistas e naturalizadas. Nesse caso, a legitimação normativa e a aplicação epistemológico-política de tais fundamentações essencialistas e naturalizadas somente podem adquirir justificação estrita e inquestionada pela centralização e monopolização institucionais desses 
processos correlatos de legitimação e aplicação, o que significa que a validade e a objetividade do credo somente são possíveis desde dentro da instituição e por meio de seu fechamento e sobreposição estruturais em relação às diferenças e à pluralidade, apagando-as, minimizando-as basicamente.

Aqui está um importante desafio às instituições de um modo geral e às instituições religioso-culturais em particular (estas, mais do que quaisquer outras, afirmam fundamentações essencialistas e naturalizadas como base para o enquadramento, para a legitimação e para a orientação da vida sociocultural e da pluralidade de sujeitos epistemológico-políticos e posições antropológicoontológicas, tornando-se fechadas, sobrepostas e autorreferenciais em relação à pluralidade): assumir de modo mais efetivo as diferenças como o ethos contemporâneo em termos antropológico-ontológicos, como a práxis normativa e como os sujeitos epistemológico-políticos fundamentais da estruturação institucional e societal. Com isso, tendo essas diferenças por base, como fundamento e sujeito epistemológico-político e estrutura antropológico-ontológica, a correlação de fundamentação e aplicação adquire outra intensidade e outra tonalidade: aqui, moderação e enfraquecimento institucionais tornam-se as palavras-chave. Com isso, as instituições religioso-culturais poderiam-deveriam assumir uma postura de abertura em termos da correlação fundamentaçãoaplicação, para que possam levar a sério e promover as diferenças qua diferenças, o que significa, se formos um pouco mais ambiciosos e radicais (e certamente mais humanos - se acreditamos, como o fazemos, de que a evolução humana também significa, e certamente de modo fundamental, aprendizado moral), trazer as diferenças para dentro das instituições e, aqui, pensar as fundamentações essencialistas e naturalizadas a partir da categoria das diferenças, tendo-as por interlocutores epistemológico-políticos privilegiados e base normativa por excelência. É o que argumentaremos no próximo capítulo a partir do diálogo entre o documento resultante do $14^{\circ}$ Sínodo dos Bispos, que teve por base a vocação e o futuro da família na Igreja Católica e no mundo contemporâneo, e a encíclica papal Amoris Laetitia, do Papa Francisco, sobre o conteúdo daquele Sínodo. 


\section{Um exemplo prático de dialética entre fundamentação e aplicação paradigmático-institucional: do 14 Sínodo dos Bispos à Encíclica Amoris Laetitia}

Queremos notar que o $14^{\circ}$ Sínodo dos Bispos se propõe a pensar o papel e a vocação da família na Igreja Católica e no, a partir do mundo contemporâneo. Nesse caso, o ethos contemporâneo é o ponto de partida e o ponto de chegada que inspira e dinamiza aquele mesmo Sínodo, orientando, assim, a própria construção de seu documento final enquanto base antropológico-ontológica e epistemológicomoral para pensarmos esse mesmo ethos contemporâneo, as diferenças, assim como os problemas da socialidade atual. Primeiramente, queremos salientar a complexidade dos desafios apresentados por esse mesmo ethos contemporâneo, conforme abordagem do Sínodo: desde problemas de integração socioeconômica abrangentes (em cada sociedade de um modo geral, nas sociedades modernas em particular), passando por crises políticas, econômicas e migratórias internacionais (em termos de globalização econômico-cultural), por crises ecológicas (dado nosso modelo de modernização consumista, tecnicista e mercadológica), passando-se ainda por diferenças culturais que impactam a constituição da família (monogâmica e heterossexual) e chegando-se, em particular, a déficits de constituição da própria modernidade ocidental, como a questão do individualismo excessivo, do feminismo irascível e do pluralismo exacerbado, que levam à consolidação do relativismo e, ao cabo, do próprio ceticismo epistemológico-moral, para não se falar de uma mentalidade contraceptiva e abortista derivada da tríade relativismo, individualismo e ceticismo (além da pobreza material, da destruição ecológica e do colonialismo acima comentados).

Além disso, nesse mesmo documento resultante do e aprovado pelo $14^{\circ}$ Sínodo, aparecem as questões de gênero e de sexualidade como representando um dos desafios mais importantes e graves quando pensamos na questão da família tanto dentro da Igreja quanto em termos de ethos contemporâneo. Surpreendentemente, somos impactados pela crítica direta à ideologia de gênero que em rigor subverteria as diferenças de gênero e a vivência da sexualidade, apagando, ao fim e ao cabo, essas mesmas diferenças constituídas em termos 
biológicos que, em verdade, são imagem e semelhança do próprio Deus. Nessa argumentação, portanto, as minorias e os movimentos ligados a gênero e sexualidade, na medida em que, conforme afirma o documento do Sínodo, apontam para e defendem o apagamento das fronteiras e das especificidades de gênero e de sexualidade (por exemplo, o que é masculino e o que é feminino), acabam dando um tiro no próprio pé, porque contradizem-se e deslegitimam-se consigo mesmos, por si mesmos. Por outras palavras: como as próprias diferenças podem defender o apagamento das diferenças em termos de gênero e de sexualidade? Isto é como que invalidar-se e negar-se a si mesmas e por si mesmas. Vejamos a passagem relativa a esta argumentação, tal como consta no documento resultante do $14^{\circ}$ Sínodo dos Bispos, para, depois, refletirmos sobre ela:

Hoje, um desafio cultural muito importante é posto pela ideologia de "gênero", que nega as diferenças e a reciprocidade naturais entre um homem e uma mulher e defende uma sociedade sem diferenças de gênero, removendo, portanto, o fundamento antropológico da família. Esta ideologia leva à consecução de programas educacionais e à realização de orientações legislativas que promovem uma identidade pessoal e uma intimidade emocional radicalmente separadas da diferença biológica entre masculino e feminino. Consequentemente, a intimidade humana torna-se uma escolha do indivíduo, que também pode mudá-la ao longo do tempo. De acordo com nossa fé, as diferenças entre os sexos representam em si mesmas a imagem e a semelhança de Deus (Gen. 1: 26-27) (SYNOD OF BISHOPS, 2015, § 8).

Analisemos as múltiplas facetas - totalmente interligadas - da crítica feita pela Igreja Católica à ideologia de gênero como um dos grandes problemas e desafios à viabilidade e efetividade tanto da diferença biológica entre homem e mulher quanto, em consequência, da família heterossexual e monogâmica, já que o que se está enfatizando aqui como modelo antropológico é exatamente (a) o fato de que a personalidade (isto é, o gênero enquanto correlação de biologia e simbolismo - ele que não é apenas uma coisa ou outra) é definida ou deveria ser definida pela nossa estrutura físico-biológica e, em particular, pelo nosso órgão sexual físicobiológico (já que, nesse caso, provavelmente é o que de mais evidente há em termos de se definir biologicamente o que é masculino, o pênis, e o que é feminino, a vagina), bem como (b) o fato consequente de que a família é união de masculino (o 
detentor do órgão sexual físico-biológico próprio do homem, do macho) e de feminino (a detentora do órgão sexual feminino, da fêmea), isto é, trata-se de uma família heterossexual. Esses são os dois primeiros pontos da passagem acima, relativa ao $14^{\circ}$ Sínodo dos Bispos, a saber, de que existe uma diferença natural, biológica entre os sexos, entre os gêneros, que é o corpo físico-biológico e, aqui, o órgão sexual físico-biológico - se nasci com pênis, sou homem, macho, e, se nasci com vagina, sou mulher, fêmea. Daqui deriva, por conseguinte, a noção de união familiar como intersecção de homem e mulher, definidos, repetimos mais uma vez, basicamente pela posse-pertença de seu órgão sexual físico-biológico respectivo. O que extrapola esta diferença físico-biológica é normativa e antropologicamente ilegítimo, uma violação a esta base natural (porque biológica) que é respaldada pela e escorada na própria criação divina, o que dá a esta base físico-biológica contornos religiosos, metafísicos.

Em segundo lugar, portanto, nós podemos perceber exatamente essa base, essa fundamentação essencialista e naturalizada como determinando a compreensão de gênero e de sexualidade, como determinando as diferenças de gênero e de sexualidade, assim como os consequentes entendimento e vivência de gênero e de sexualidade de um modo mais geral. Por fundamentos essencialistas e naturalizados, queremos - e o Sínodo quer - significar o fato de que gênero e sexualidade não são uma criação humana localizada no espaço e no tempo e em termos socioculturais, definida por estes, uma escolha que podemos fazer como quando fazemos compras e escolhemos qual camisa queremos ou não queremos comprar-vestir; de fato, gênero e sexualidade são determinações correlatamente religiosas e biológicas, com as quais nascemos desde sempre e para sempre. Eles não estão, de modo estrito, submetidos ao sentido historicista e culturalista (e até individualista) da vida, o que significa, como consequência, que sobre eles não incide o pluralismo, o relativismo e o ceticismo estritos, assim como aquele individualismo exacerbado comentado de passagem acima: o órgão sexual físicobiológico com o qual nascemos determina a personalidade que teremos, nossa pertença e definição de gênero e, finalmente, o tipo de sexualidade que teremos 
(incluiremos reprodução biológica na sexualidade e também ligada ao órgão sexual físico-biológico, no sentido de que sexualidade já carrega também o significado de reprodução sexual). É por isso que o individualismo, o feminismo, o culturalismo, o relativismo e o ceticismo excessivos e teimosos podem desvirtuar a família na medida em que não se leva a sério essa base essencialista e naturalizada de gênero e de sexualidade. É por isso, finalmente, que essa mesma base essencialista e naturalizada serve de fundamento normativo paradigmático para o enquadramento, para a crítica e para a legitimação de todos os valores, códigos, práticas e sujeitos epistemológico-políticos ligados a gênero e a sexualidade, em qualquer contexto, para qualquer contexto.

A terceira característica fundamental daquela passagem, ainda que implícita, consiste na correlação de institucionalização, objetividade forte e fundamentações essencialistas e naturalizadas que leva ao fundamentalismo epistemológico-político-normativo, de modo a tornar a legitimação e a aplicação dos valores, das normas e dos sujeitos epistemológico-políticos basilares do credo uma práxis institucionalizada autorreferencial, autônoma e auto-subsistente, localizada para além do cotidiano, dentro das e internas às instituições, sobreposta, em grande medida, aos crentes e aos não-crentes, uma práxis que também se coloca como verticalizada, de cima para baixo, por sobre as cabeças desses mesmos crentes e não-crentes, não assumindo com radicalidade as particularidades e contingências próprias do pluralismo cotidiano. Senão vejamos. A instituiçãoinstitucionalização como fenômeno fundante da cultura ocidental é marcada pelo fato de que a construção e a fundamentação do conhecimento e da ação válidos, objetivos, socialmente vinculantes são, constituem-se e dinamizam-se como uma práxis que se funda na e que depende basicamente da instituiçãoinstitucionalização. Somente ela e por ela se conseguiria sintetizar e unificar a pluralidade amorfa e confusa de posições antropológico-ontológicas, de valores e práticas normativos e de sujeitos epistemológico-políticos do dia a dia. Somente ela, no mesmo diapasão, permitiria a superação do individualismo, do relativismo e do ceticismo epistemológico-morais, que se baseiam exatamente na pluralidade de 
visões de mundo, de valores e de sujeitos epistemológico-políticos. A instituição, por meio da institucionalização, possibilita correlatamente a depuração-síntese do senso comum, a formação, a partir disso, de um paradigma epistemológico-moral objetivo ou universal e, depois, consequentemente, sua aplicação àquele senso comum plural e amorfo via política e educação e missionarização. Nesse sentido, a instituição, por meio da institucionalização, adquire um papel de médium, de ponte, de caminho a partir do qual e por meio do qual o senso comum é superado por uma visão filosófica-teológica-científica de mundo que é objetiva e justificada a partir de procedimentos, de valores e de sujeitos epistemológico-políticos institucionalizados. Ela diria e realizaria a objetividade, a legitimação e a validade do conhecimento e da ação justificados e, por causa disso, teria legitimidade para assumir essa função de ponta de lança no que diz respeito à crítica, ao enquadramento e à orientação da evolução social, dos processos de socialização e de subjetivação. Esta é a herança platônica fundamental e imorredoura assumida, nesta ordem, pela filosofia, pela teologia e, depois, pela ciência natural como a base da constituição das instituições, da produção e da fundamentação do conhecimento e da ação, bem como das relações entre ciência, política e educação. Aqui, a correlação de ciência, institucionalização e poder é clara e direta, apontando exatamente para o primado epistemológico-político da instituição e da institucionalização como, respectivamente, a base-sujeito normativo e epistemológico-político e a práxis epistemológica-política-normativa fundamentais.

Nessa descrição do processo de institucionalização e nessa autocompreensão das instituições ocidentais, o movimento de auto-constituição, de auto-legitimação e de auto-evolução dessas mesmas instituições é bem claro: superação do senso comum e desenvolvimento de uma visão científica de mundo, superação do pluralismo, do relativismo, do ceticismo e do individualismo por um paradigma antropológico-ontológico e epistemológico-moral objetivos e universais; e orientação desse mesmo senso comum a partir deste paradigma sustentado, legitimado e utilizado pelas instituições frente àquele mesmo senso comum. Ora, 
aqui aparece aquela imbricação entre institucionalismo forte, objetividade epistemológico-moral e antropológico-ontológica estritas e fundamentalismo político-normativo, uma correlação que gostaríamos de explicar melhor para evitar-se mal entendidos. Por institucionalismo forte, queremos significar o fato de que a institucionalização é um procedimento autorreferencial, autônomo, autosubsistente e fechado, em grande medida, relativamente ao senso comum e aos sujeitos epistemológico-políticos do senso comum, no sentido de que as elites institucionais (filósofos, teólogos e cientistas) assumem papel epistemológicopolítico-normativo central no que diz respeito à constituição, à legitimação e ao fomento social do credo. Como conseqüência, por este termo também estendemos o fato de que a instituição centraliza e monopoliza a constituição, a legitimação e o fomento social do credo, tornando-se a base paradigmática, o médium e o sujeito epistemológico-político fundamentais desse mesmo credo e de sua dinamização ao longo do tempo. Por objetividade antropológico-ontológica e epistemológicomoral estritas entendemos exatamente a ideia de que essa objetividade ou universalidade é a condição - a única condição - para a orientação, para o enquadramento e para o sentido da pluralidade, de modo que é a partir dela que essa mesma pluralidade pode ser entendida, protegida e legitimada: a pluralidade somente teria voz e vez a partir dessa unidade. Aqui, essa objetividade ou universalidade estrita leva à utilização de fundamentações essencialistas e naturalizadas - especialmente em teologia - que pressupõem que a pluralidade tenha um núcleo antropológico-ontológico de base biológico-religiosa que garante a unidade do gênero humano, sua gênese e sua destinação final comuns, embasando, garantindo e dinamizando essa mesma objetividade e sua ligação com o pluralismo, seu sentido primigênio ontogenicamente falando relativamente ao pluralismo. Por fim, por fundamentalismo político-normativo entendemos o fato de que a institucionalização e a centralização-monopolização institucional da constituição, da legitimação e da aplicação do credo, dada esta organização e este funcionamento autorreferenciais e auto-subsistentes da própria instituição frente ao senso comum e às pessoas comuns, é feita de modo verticalizado, de cima para 
baixo, das elites institucionais para as pessoas comuns, da instituição para o senso comum, e a partir daqueles fundamentos essencialistas e naturalizados que possuem uma tendência totalizante, salvífico-messiânica e universalista: eles se referem a todos, eles são para todos e eles controlam-regulamentam todos os âmbitos da vida humana, em qualquer área, em qualquer contexto e para quaisquer sujeitos epistemológico-políticos.

É aqui que a dialética entre fundamentação e aplicação dos paradigmas antropológico-ontológicos e epistemológico-morais via instituição e por meio da institucionalização torna-se aguda e pungente, porque ela se baseia exatamente na e é dinamizada exatamente pela correlação-oposição entre institucionalização naquela correlação de institucionalismo forte, fundamentações essencialistas e naturalizadas e fundamentalismo político-normativo - e diferenças, unidade antropológico-ontológica e epistemológico-moral e pluralidade de valores, de práticas e de sujeitos epistemológico-políticos. Ora, nessa dialética, um institucionalismo forte, fundado em bases essencialistas e naturalizadas e impondo uma aplicação fundamentalista estrita e verticalizada (no sentido acima explicitado) dos paradigmas antropológico-ontológicos e epistemológico-morais não apenas não consegue efetivamente captar a singularidade e a carnalidade das diferenças, senão que tende a minimizá-las, a negá-las, a deslegitimá-las e, finalmente, mas não menos importante, a concebê-las em um sentido às vezes bastante pejorativo - com isso, essa correlação de institucionalismo forte, fundamentações essencialistas e naturalizadas (ou objetividade forte e estrita) e fundamentalismo político-normativo tende a solapar a voz-práxis das diferenças, as diferenças como práxis, instituindo um discurso-práxis institucionalizado que é grandemente totalizante, unidimensional e massificador. É por isso que a encíclica Amoris Laetitia, escrita pelo Papa Francisco, surpreende muito positivamente pela sua sensibilidade e inteligência - que não significam em absoluto fraqueza, mas exatamente isso: sensibilidade e inteligência -, assumindo um protagonismo político-normativo que poucas instituições religiosas - e, se pensarmos no Brasil, também poucas instituições políticas - possuem e apresentam hodiernamente. 
Conforme pensamos, é exatamente aquela correlação de institucionalismo forte, fundamentações essencialistas e naturalizadas e fundamentalismo políticonormativo que é enquadrada pela referida encíclica, o que significa, como consequência, que a dialética entre fundamentação dessa base essencialista e naturalizada e aplicação dela à pluralidade não pode simplesmente adquirir um sentido e uma literalidade estritas e nem uma imposição verticalizada pura e simplesmente por parte da instituição aos crentes e aos não-crentes, sem um diálogo e uma práxis interativa mais efetivos, abertos e participativos.

É por isso que, nessa encíclica, aparecem o tempo todo, como uma constante norteadora e normativa, termos como "gradualidade da pastoral" (Papa Francisco, 2016, § 293, p. 230), "discernimento pastoral” (Papa Francisco, 2016, § 293, p. 231), "lei da gradualidade" (Papa Francisco, 2016, § 295, p. 232-233), "lógica da integração" (Papa Francisco, 2016, § 299, p. 237), "exigências evangélicas de verdade de caridade" (Papa Francisco, 2016, § 300, p. 239), “discernimento responsável” (Papa Francisco, 2016, § 303, p. 242), “caridade” e “misericórdia”, etc. Ora, seu objetivo é simples: alertar que a dialética entre fundamentação e aplicação não é um exercício de simples imposição vertical de fundamentações essencialistas e naturalizadas à pluralidade de posições antropológico-ontológicas e de sujeitos epistemológico-políticos, mas sim uma práxis marcada pela sensibilidade, reflexividade e moderação. Referindo-se a tal dialética e ao contexto do pluralismo e ao sentido da práxis missionária em termos de aplicação paradigmática, o Papa Francisco diz como instituição:

temos de evitar juízos que não tenham em conta a complexidade das diversas situações e é necessário estarmos atentos ao modo em que as pessoas vivem e sofrem por causa de sua condição (PAPA FRANCISCO, 2016, § 296, p. 234).

Obviamente, esta passagem precisa ser localizada dentro do contexto maior da fala e da preocupação do Papa Francisco, que já anteriormente fôra debatido pelo Sínodo, a saber, a integração na Igreja de divorciados e de pessoas que casamse novamente. É a estes casos que a afirmação acima se refere diretamente. Porém, 
veja-se a sensibilidade e a inteligência - e certamente também o alcance - desta afirmação do sumo pontífice. Ela pode ser situada exatamente em nosso argumento de que a dialética entre fundamentação e aplicação necessita de sensibilidade, de moderação, de reflexividade e, às vezes, de renúncia do fundamentalismo políticonormativo estrito e verticalizado, o que significa, portanto, uma reconstrução e uma reformulação institucionais relativamente ao entendimento dado pela instituição às diferenças, bem como a aplicação institucional desse entendimento às diferenças, nas diferenças. Nesse sentido, nem sempre a correlação entre institucionalismo forte, fundamentações essencialistas e naturalizadas e fundamentalismo político-normativo funciona efetivamente como base da dialética entre fundamentação e aplicação, entre instituição-institucionalização e diferenças. Isso pode ser percebido em três passagens que consideramos fundamentais e magníficas (por suas conseqüências antropológico-ontológicas, epistemológicomorais e em termos de reformulação institucional). Citemo-las. A primeira referese diretamente à aplicação paradigmática frente às diferenças, nelas:

É mesquinho deter-se a considerar apenas se o agir de uma pessoa corresponde ou não a uma lei ou norma geral, porque isto não basta para discernir e assegurar uma plena fidelidade a Deus na existência concreta de um ser humano. [...] É verdade que as normas gerais apresentam um bem que nunca se deve ignorar nem transcurar, mas, na sua formulação, não podem abarcar absolutamente todas as situações particulares (PAPA FRANCISCO, 2016, §304, p. 243).

Ora, é exatamente porque a fundamentação da objetividade antropológicoontológica e epistemológico-moral unidimensionalizadas não pode assimilar, abarcar e orientar de modo totalizante todos os aspectos da existência humana, todas as suas nuances, não podendo também enquadrar-controlar e falar-agir, como fala-práxis, a todos e por todos os sujeitos epistemológico-políticos que, primeiro, a escuta e a participação desses mesmos sujeitos epistemológico-políticos se fazem absolutamente necessárias para o exercício de constituição-legitimaçãofuncionamento institucional, bem como, segundo, a moderação, a reflexividade e a sensibilidade - e, às vezes, a própria renúncia - institucionais em termos de aplicação paradigmática se tornam o eixo normativo da práxis e como práxis. É 
como se Papa Francisco dissesse: mesmo que utilizemos fundamentações essencialistas e naturalizadas como base tanto da estruturação e do funcionamento institucionais quanto da compreensão do ser humano e do enquadramento das diferenças de um modo mais geral, entendamos que uma coisa é a fundamentação institucional e por meio da institucionalização e outra coisa - às vezes completamente diferente e divergente - a sua aplicação no contexto sociocultural e ao pluralismo de sujeitos epistemológico-políticos. É por isso que, de acordo com o Papa Francisco, a caridade e a misericórdia devem, de fato, nortear uma tal dialética entre fundamentação e aplicação, entre instituição-institucionalização e diferenças. Ora, a centralidade da caridade e da misericórdia impactam - e isso queremos enfatizar fortemente - a própria constituição institucional do credo que deve, em primeiro lugar, estar fundado nelas e dinamizado-sensibilizado por elas. “Por isso, convém sempre considerar 'inadequada’ qualquer concepção teológica que, em última instância, ponha em dúvida a própria onipotência de Deus e, especialmente, a sua misericórdia” (PAPA FRANCISCO, 2016, § 311, p. 250).

Note-se, aqui, como forma de situar essa passagem no contexto de Amoris Laetitia, que a onipotência de Deus é sua misericórdia e, com isso, o nosso mote basilar para sermos fiéis e obedientes a esta mesma onipotência divina (e à gratuidade da graça da vida e da salvação) é sermos - nós, a instituição Igreja, que fundamentamos e aplicamos paradigmas à pluralidade - misericordiosos com todos aqueles que não se enquadram em nossa base paradigmática essencialista e naturalizada. Esse é o contexto e o sentido da citação acima, pura e simplesmente, diretamente. Com isso, a constituição da teologia, se por um lado se compromete exatamente com a legitimação e a utilização de bases essencialistas e naturalizadas, por outro não pode esquecer-se da e nem abandonar a sensibilidade, a caridade $e a$ misericórdia para com as diferenças, que impedem a aplicação estrita, verticalizada e fundamentalista desses paradigmas essencialistas e naturalizados. 
O ensino de teologia moral não deveria deixar de assumir estas considerações, porque, embora seja verdade que é preciso ter cuidado com a integralidade da doutrina moral da Igreja, todavia sempre se deve pôr um cuidado especial em evidenciar e encorajar os valores mais altos e centrais do Evangelho, particularmente o primado da caridade como resposta à iniciativa gratuita do amor de Deus. Às vezes, nos custa muito dar lugar, na pastoral, ao amor incondicionado de Deus. Pomos tantas condições à misericórdia que a esvaziamos de sentido concreto e real significado, e esta é a pior maneira de aguar o Evangelho (PAPA FRANCISCO, 2016, § 311, p. 249-250).

Nesse sentido, a superação de "uma moral fria de escritório" (PAPA FRANCISCO, 2016, § 312, p. 251) e a consideração da Igreja não como "uma alfândega", mas sim como "a casa paterna, onde há lugar para todos com a sua vida fadigosa" (Papa Francisco, 2016, § 310, p. 249), acontecem por meio da sensibilidade e do discernimento acerca da fundamentação paradigmática institucionalizada e de sua aplicação às diferenças, sensibilidade e discernimento que aparecem como estando embasados na caridade e na misericórdia, na percepção de que a alteridade foge de uma unidimensionalização, de uma homogeneização e de um enquadramento estritos, permanecendo sempre um mistério em termos de ininteligibilidade estrita e profunda. Aqui, somente o amor incondicional, a abertura, a sensibilidade e o acolhimento institucionais, a vozpráxis das próprias diferenças e com elas e por elas, podem nos dar referenciais mínimos e uma base paradigmático-normativa fundante para a interação. À guisa de conclusão, nossas reflexões nos permitem defendermos dois pontos fundamentais para pensarmos a dialética entre fundamentação paradigmática e aplicação desses paradigmas às diferenças, para pensarmos a dialética entre instituição-institucionalização e diferenças. O primeiro deles, como pudemos perceber a partir da consideração da encíclica Amoris Laetitia, do Papa Francisco, aponta para o fato de que não há um caminho reto e fácil entre fundamentação e aplicação, de modo que temos de diferenciá-las enquanto momentos singulares e nem sempre totalmente correlatos: não se pode aplicar a bel-prazer, vertical e dogmaticamente e de modo insensível um paradigma antropológico-ontológico e epistemológico-moral institucionalizado, de tendência totalizante $\mathrm{e}$ unidimensionalizante, à pluralidade de visões de mundo e de sujeitos 
epistemológico-políticos. Aqui, são necessárias sensibilidade, abertura, moderação e discernimento.

O segundo deles, e aqui já estamos apontando para mais além de Amoris Laetitia (mas ligados afetiva e normativamente a ela), o gradual enfraquecimento e eventualmente abandono de fundamentações essencialistas e naturalizadas, pelo menos em alguns campos específicos da vida humana e sociocultural, em particular em termos de gênero e de sexualidade. O pluralismo antropológico-ontológico e epistemológico-moral, as diferenças irredutíveis apontam para isso, exigem diretamente isso. Talvez aqui esteja o grande desafio e também o futuro da sociabilidade humana e da estruturação e do funcionamento das instituições como ethos propriamente contemporâneo, isto é, a centralidade das diferenças por meio do enfraquecimento e até do abandono de fundamentações essencialistas e naturalizadas por parte das religiões institucionalizadas e universalistas, que passariam a se concentrar mais na espiritualidade e no amor (como não-poder, como superação das bases essencialistas e naturalizadas) e menos na correlação institucionalismo forte, objetividade antropológico-ontológica e epistemológicomoral estritas e fundamentalismo político-normativo.

Nesse sentido, fazendo referência uma vez mais à afirmação do $14^{0}$ Sínodo, em sua crítica à ideologia de gênero, de que as diferenças estariam propondo, ao contraporem-se às fundamentações essencialistas e naturalizadas em termos de gênero e de sexualidade (fundamentações essencialistas e naturalizadas que foram assumidas diretamente por este $14^{\circ}$ Sínodo), o apagamento das fronteiras de gênero e de sexualidade, o que seria contraditório, posto que as anularia enquanto diferenças; fazendo referência, ainda relativamente a este $14^{\circ}$ Sínodo, de que as diferenças somente serão protegidas, promovidas e fomentadas exatamente por meio daquela base essencialista e naturalizada, e não por meio do apagamento das diferenças, cumpre-nos dizer há uma incompreensão muito clara, por parte do Sínodo, em relação a tal práxis dessas diferenças: não se trata do apagamento das diferenças nem é essa a bandeira dos movimentos ligados a gênero e a sexualidade. 
O que se quer é exatamente enfatizar as diferenças como contraponto e como práxis corretiva e certamente limitadora das fundamentações essencialistas e naturalizadas, como práxis corretiva e limitadora da correlação entre institucionalismo forte, objetividade epistemológico-moral e antropológicoontológica estritas e fundamentalismo político-normativo, o que implica no repensar da imbricação entre fundamentação e aplicação paradigmáticas. Com isso, não é a ideologia de gênero que apaga ou subverte as diferenças entre os sexos, as diferenças e reestilizações de gênero e de sexualidade, mas sim fundamentações essencialistas e naturalizadas que, impostas desde dentro das instituições religioso-culturais para o contexto sociocultural e político-normativo mais amplo dos cidadãos e das cidadãs, dos crentes e dos não-crentes, assumem um sentido totalizante, unidimensional e enquadrador de todos os sujeitos epistemológico-políticos e de todas as práticas antropológico-ontológicas.

Tais fundamentações essencialistas e naturalizadas totalizantes percebem, legitimam e orientam exatamente o apagamento das diferenças, na medida em que ligam a definição do gênero e da sexualidade, da diferenciação de gênero e da vivência da sexualidade ao corpo físico-biológico, ao órgão sexual físico-biológico que temos como (corpo físico-biológico) masculino e (corpo físico-biológico) feminino, dando, inclusive, um sentido religioso-metafísico a esta estrutura físicobiológica e esquecendo-se totalmente de suas dinâmicas e vinculações simbólicoculturais contextualistas e historicistas (e mesmo individualistas, em muitos casos). Ora, nos parece que as diferenças - e, nesse caso, as diferenças de gênero e de sexualidade - apontam exatamente para o fato de que essas mesmas diferenças já não podem ser enquadradas, legitimadas ou deslegitimadas e conceituadas como e a partir do corpo físico-biológico, a partir do órgão sexual físico-biológico com o qual nascemos, pelo menos não apenas como e a partir do corpo físico-biológico, do órgão sexual físico-biológico. Por isso, reforçamos mais uma vez, a importância tanto da sensibilidade, da abertura e da moderação em termos de dialética entre fundamentação e aplicação paradigmáticas, entre instituição-institucionalização e diferenças, quanto do gradativo enfraquecimento e abandono de fundamentações 
essencialistas e naturalizadas relativamente a campos específicos da vida humana, em especial gênero e sexualidade.

\section{Considerações finais}

Aqui chegados, queremos reforçar o argumento desenvolvido ao longo do texto. Para as religiões institucionalizadas e universalistas, a afirmação das diferenças como ethos e práxis contemporâneos é uma verdadeira benção e uma efetiva redenção, por assim dizer. As diferenças, dado seu sentido singular e irredutível, alertam permanentemente para o perigo da negação e da violência simbólico-materiais causadas pela imposição institucional verticalizada de paradigmas antropológico-ontológicos e epistemológico-políticos totalizantes, calcados em fundamentações essencialistas e naturalizadas que acreditam poder subsumir, enquadrar e orientar todos os sujeitos epistemológico-políticos e, de um modo mais geral, todas as esferas da vida humana, sem qualquer diálogo, sem qualquer moderação, sem qualquer sensibilidade. Nesse sentido, as diferenças e sua centralidade, como ethos e práxis contemporâneos, permitem a redenção das instituições em um duplo sentido: a correção de seu institucionalismo forte, muitas vezes insensível às diferenças e com pretensão de controle e imposição totalizantes e unidimensionais de formas de vida, de valores e de práticas a todos os sujeitos epistemológico-políticos; e o alívio dessa sua tarefa de, por meio do credo em bases essencialistas e naturalizadas, buscar esse mesmo controle e direção de todos os aspectos da vida humana. Doravante, tendo-se por base as diferenças como ethos e práxis contemporâneos, as religiões podem deixar a vivência cotidiana de gênero e de sexualidade à escolha dos indivíduos e dos grupos socioculturais, dedicando-se de modo mais estrito e efetivo à dinamização da espiritualidade, à mediação do diálogo intercultural e à proteção das minorias político-culturais enquanto práxis institucional por excelência para este século XXI.

Por isso, conforme acreditamos, o grande desafio posto pela dialética entre diferenças e religiões institucionalizadas e universalistas, em termos de 
constituição-fundamentação teológica e sua aplicação político-normativa no contexto sociocultural, aponta para a moderação e o enfraquecimento das fundamentações essencialistas e naturalizadas e, com isso, para a moderação e o enfraquecimento do institucionalismo forte no que diz respeito à estruturação, à legitimação e à vinculação sociocultural das religiões institucionalizadas e universalistas. Não por acaso, essa é a invectiva e o convite propostos pelo Papa Francisco em sua encíclica Amoris Laetitia, a saber, a sensibilidade, o discernimento, a proximidade, o diálogo-escuta relativamente às diferenças, a tudo aquilo que não pode ser subsumido pura e simplesmente na correlação de fundamentações essencialistas e naturalizadas e institucionalismo forte. Talvez por isso o Papa Francisco, em Amoris Laetitia, coloque grande responsabilidade sob os ombros seja dos teólogos, seja dos sacerdotes e religiosos em geral, no que diz respeito à constituição-fundamentação do credo e à sua aplicação no contexto sociocultural mais amplo e diante do pluralismo: os religiosos são o sujeito epistemológico-político e a frente normativa fundamentais que interligam credo e sociedade, instituição e diferenças. Aqui, o que a instituição é de dentro para fora (e de fora para dentro) acaba sendo definido pela própria práxis dos religiosos, isto é, dos sujeitos epistemológico-políticos institucionalizados em sua aplicação do credo à sociedade, às diferenças, com elas e para elas.

\section{REFERÊNCIAS}

AQUINO, Santo Tomás de. De regno. Petrópolis: Vozes, 1997.

AgOStinhO, Santo. A cidade de Deus. Lisboa: Fundação Calouste Gulbenkian, 1991.

ARISTÓTELES. Ética a Nicômacos. São Paulo: Nova Cultural, 1991.

ARISTÓTELES. Política. Brasília: Editora da UNB, 1997.

FORST, Rainer. Contextos da justiça: filosofia política para além de liberalismo e comunitarismo. São Paulo: Boitempo, 2010.

HABERMAS, Jürgen. Direito e democracia: entre facticidade e validade (Vol. I). Rio de Janeiro: Tempo Brasileiro, 2003. 
HABERMAS, Jürgen. A inclusão do outro: estudos de teoria política. São Paulo: Loyola, 2002.

HONNETH, Axel. Luta por reconhecimento: a gramática moral dos conflitos sociais. São Paulo: Editora 34, 2003.

HONNETH, Axel. Reificación: un estúdio en la teoría del reconocimiento. Buenos Aires: Katz, 2007.

KOPENAWA, Davi; ALBERT, Bruce. A queda do céu: palavras de um xamã yanomami. São Paulo: Companhia das Letras, 2015.

LÉVINAS, Emmanuel. Entre nós: ensaios sobre a alteridade. Petrópolis: Vozes, 1997.

MARX, Karl. Manuscritos econômico-filosóficos. São Paulo: Martins Claret, 2013.

MARX, Karl; ENGELS, Friedrich. A ideologia alemã. São Paulo: Martins Fontes, 2008.

PAPA FRANCISCO. Amoris Laetitia. Vaticano: Tipografia Vaticana, 2016. Disponível em: <http://www.agencia.ecclesia.pt/netimages/file/papa-francesco_esortazioneap_20160319_amoris-laetitia_po.pdf $>$. Acesso em: 28 mar. 2017.

PLATÃO. A República. Lisboa: Fundação Calouste Gulbenkian, 2002.

RAWLS, John. O liberalismo político. São Paulo: Ática, 2002.

RORTY, Richard. Uma ética laica. São Paulo: Martins Fontes, 2010.

SYNOD OF BISHOPS. XIV Ordinary Assembly. The Vocation of the Family in the Church and in the Contemporary World. The Final Report of the Synod of Bishops to the Holy Father, Pope Francis. 24 Oct. 2015. Disponível em:

<http://www.vatican.va/roman_curia/synod/documents/rc_synod_doc_20151026_relaz ione-finale-xiv-assemblea_en.html>. Acesso: 28 mar. 2017. 